\title{
Sensitivity analysis of WUFI simulations of a traditional brick building
}

\author{
P.H. Baker ${ }^{\mathrm{a} *}$ and S. Rhee-Duverne ${ }^{\mathrm{b}}$ \\ a Glasgow Caledonian University, Glasgow, UK \\ $b$ Historic England, London, UK
}

\begin{abstract}
Traditional bricks have a range of properties which may be unknown, thus their impact on moisture risk is uncertain. Selecting an inappropriate material for hygrothermal modelling can produce misleading simulation results. A sensitivity analysis using WUFI-Pro was performed using different 'library' bricks to investigate the influence of brick properties in modelling a Victorian terrace house upgraded with IWI. Results were categorised by a seasonal 'amplitude', the difference between the highest and lowest monthly average relative humidity at the brick/IWI interface. Moisture diffusivity best explained the differences in the moisture response. Two bricks produced results consistent with brick/IWI interface measurements in the house. The study illustrated the need for guidance in choosing materials and conventions for modelling to assess moisture risk.
\end{abstract}

Peer-review under the responsibility of the organizing committee of the ICMB21.

Keywords: Hygrothermal simulation; traditional brick properties; retrofit.

\section{Introduction/Background}

Modelling of heat and moisture transport, hygrothermal simulation, is commonly used as a means of assessing the risk of moisture problems in traditional buildings, particularly if the intention is to upgrade a building's thermal performance by applying internal insulation. However, to achieve meaningful results it is important to correctly specify the construction details of the building including materials and orientation, also have some knowledge of the local climate and the internal environment. Often the actual material properties of traditional building materials are unknown, therefore caution should be exercised as selecting an inappropriate material for hygrothermal modelling can produce misleading simulation results. WUFI requires complex material property data, which are not available for many materials, especially those from traditional buildings and are difficult to measure. Although there is a large database of material properties within WUFI, there is currently no guidance as how to choose a material from the database and therefore how closely the results from the modelling represent the real conditions in the building.

\section{Aims \& Objectives}

The overall aims of the study were to carry out an extensive sensitivity analysis using the hygrothermal simulation program WUFI® Pro 5 to:

- Investigate the influence of brick properties in models of a construction currently being monitored by Historic England in a Victorian terrace house at New Bolsover, Derbyshire. The house is constructed of $230 \mathrm{~mm}$ thick brick walls and two internal wall insulation systems, PIR and Woodfibre, were applied as part of a series of measures to upgrade its thermal performance. 37 bricks available in the WUFI database were considered with a range of hygrothermal properties.

- Identify bricks which produce results consistent with brick/IWI interface measurements in the terrace house.

- Determine which moisture storage and transport properties of brick (for example porosity, moisture absorption, diffusion resistance) have a significant impact on the dynamic conditions at the brick/insulation interface and the moisture risk of the constructions, particularly the insulation systems.

- Investigate orientation effects due to solar radiation and driving rain.

\section{Methodology}

For the first part of the study, basic local weather data consisting of temperature and relative humidity (RH) were used to exclude orientation effects resulting from other weather variables: rain, wind and solar radiation. Measured indoor temperature and RH from the New Bolsover house were used. Simulations were carried out for the wall construction with both insulation systems and the 37 bricks. The modelled temperature and humidity results at the interface between the brick and insulation systems are considered as the key outputs of the simulations, since the cold side of the insulation is most at risk from interstitial condensation. The seasonal behaviour of the interface RH results were analysed to determine relationships with brick properties to identify the key material properties which have the most significant impact.

* Corresponding author. +44 7909362486.phowbak@gmail.com. 


\section{ICMB21}

The orientation effects of solar radiation and driving rain were modelled using from the nearest Met Office at Watnall, Nottinghamshire for the year 2015 and the complete room temperature and humidity data from the New Bolsover house were collected during 2015. Driving rain on each elevation of interest was calculated as hourly Airfield Hourly Indices following BS EN ISO 15927-3:2009 [1]. A Rain Adherence Factor (RAF), which estimates the amount of rain being absorbed v. splashed back, was applied in WUFI to simulate the fraction of the driving rain absorbed by a wall. This value was varied in a series of simulations.

\section{Summary of Results}

Inspection of the data plots of simulation results for the 37 bricks showed a wide range of brick/insulation interface RH results, which could be categorised by

1. 'Amplitude', the difference between the highest and lowest monthly mean values of $\mathrm{RH}$, and

2. The months with the highest and lowest monthly mean values of RH.

The trends of the interface RH results with brick properties showed amplitude and moisture storage (the sorption relationship between moisture content and $\mathrm{RH}$ ) appeared to be the strongest with low moisture capacity bricks giving the highest amplitudes, where moisture capacity is defined as the slope of the moisture storage function. In general, bricks with lower moisture capacity and higher ability to transport moisture produce more rapid seasonal changes in RH at the interface in response to the boundary conditions than bricks with higher moisture capacity and lower moisture transport. The moisture diffusivity, a function of the vapour permeability and moisture capacity of the bricks, over the range of seasonal behaviour appears to be the factor which gives the best explanation for the differences in the moisture response of at the interface. Overall, the analysis of the results for both insulation systems shows that moisture diffusivity correlates strongly with seasonal amplitude: higher diffusivity results in greater seasonal amplitude.

The brick properties have negligible influence on the behaviour of the PIR insulation since the foil facings on the PIR boards limit vapour transfer through the insulation. The woodfibre insulation is significantly influenced by the brick properties. For bricks with low moisture capacity, similar to the New Bolsover brick, the woodfibre effectively buffers moisture during the periods with high humidity when the bricks are unable to store or transfer moisture and release moisture during the summer. The effect is less pronounced for bricks with higher moisture capacity, where moisture is transferred into the bricks rather than the woodfibre during periods of high humidity.

The simulation results show that the higher the incident solar radiation the higher the external surface and interface temperatures, with the most noticeable effect due to incident solar radiation on the west elevation. High temperatures tend to result in lower interface relative humidities. The effect is more pronounced for lower moisture capacity brick than for bricks with high moisture buffering capacity. The driving rain simulations results combined the effects of driving rain and incident solar radiation on an elevation. The results are also sensitive to brick type and the IWI system. The low moisture capacity bricks are more sensitive to increases in the RAF applied in the simulations, resulting in higher interface relative humidities from the same driving rain impacting on the high moisture capacity bricks. The vapour permeable woodfibre IWI system, as it is capillary active, is more responsive to changes in driving rain and seasonal climate than the PIR system; this is particularly noticeable with the lower moisture capacity bricks.

\section{Conclusions}

Generally, a cautious approach should be adopted when selecting suitable materials from the WUFI database for the simulation of a construction where the material properties are unknown, since a wide range of possible results are likely depending on the selected materials. This is particularly relevant when dealing with brick and stone constructions which have a wide range of material properties. In a retrofit, such as IWI at New Bolsover, prior knowledge of the brick properties would have been useful to predict the likely performance of the walls with the two IWI systems, however insufficient material was available for testing. Measurements of the pore size distribution, carried out with small quantities of material, may be useful since the distribution is linked to absorption, moisture capacity and capillary active pores [2]. This is recommended as an area of interest for further research which may also be relevant to the absorption of driving rain.

The determination of a suitable RAF is a concern: if there are measured rain and building fabric data available, model validation can be carried out and an appropriate RAF identified. Generally, this is an unknown. The driving rain simulations show that the moisture capacity of the brick type is an important factor. Given these uncertainties, a series of RAF should be tried to establish the possible range of responses to driving rain of a construction.

The sensitivity study has been able to identify suitable candidates from the WUFI database which produces simulated results which are consistent with the seasonal behaviour shown by monitored data from the New Bolsover house.

The study illustrated the need for guidance in choosing materials and conventions for dynamic modelling to assess moisture risk.

\section{References}

[1] BS EN ISO 15927-3:2009, Hygrothermal performance of buildings - Calculation and presentation of climatic data - Part 3: Calculation of a driving rain index for vertical surfaces from hourly wind and rain data). BSI, London.

[2] Larsen P.K. (1995) Moisture physical properties of bricks, Technical Report 343, Building Materials Laboratory, Technical University of Denmark. ISSN 0908-3871. 